\title{
Analysis of Chinese Children's Nutrition Health Situation and Influencing Factors
}

\author{
Li Yi \\ School of Tourism of Huangshan University, Huangshan, Anhui, A, China
}

\begin{abstract}
Using the China Health and Nutrition Survey (CHNS), this paper analyses that height for age (HAZ) of children from urban area is higher than that of those from rural areas on average and the height varies among rural children. Gender also has similar impact on children's height, namely, HAZ of girls is lower than that of boys. In addition, only children has better nutrition health than others and living with parents or not has great impact on children's nutrition health as well.
\end{abstract}

\section{Introduction}

As an important indicator of national health and living standards, children's health has always been a key issue of research in developing countries. There are many factors affecting children's nutrition and health and their influence is of different degree. But in general, children's health is mainly affected by three aspects: personal physique, family environment and community environment.

\section{Child health status quantification model}

Health itself is not a simple and perceptible single indicator. Gerdtham, Johannesson (1999) and Zhao Zhong (2006) all use self-assessed health status as a measure of health, but for children, especially low-age children, they lack the judgment of their own health. Conversely, the Height for Age Z-score (HAZ) is relatively more commonly used. This indicator calculates the height of a child compared with the average height of the standard population recommended by the World Health Organization by age and gender, and is divided by the standard population age-specific height standard and then get the child's deviation from the population's age-to-height standard deviation, reflecting the child's long-term nutritional status, which is also the measure of child development status recommended by World Health Organization. Therefore, this article uses this indicator to calculate the $\mathrm{z}$-score value, with Hi Indicating the health status of the i-th child.

Since children's health is affected by social-economic factors such as individual physique and family and community environment, the influencing factors of child health $\mathrm{H}$ can be quantified by model, expressed as a function:

$\mathrm{H}=\mathrm{F} \quad\left(\mathrm{X}_{\mathrm{j}}, \mathrm{X}_{\mathrm{f}}, \mathrm{X}_{\mathrm{c}, \mu}\right)$

According to (1), a multiple linear regression model of children's health influencing factors can be further constructed:

$\mathrm{Hi}=\beta 0+\beta 1 \mathrm{Xi}+\beta 2 \mathrm{Xf}+\beta 3 \mathrm{Xc}+\mu$

$\mathrm{X}_{\mathrm{i}}$ indicates the characteristic variables of the child, including the child's age, gender, whether it is vaccinated, whether it has received health care services and other indicators. $X_{f}$ is a family characteristic variable, including the family's per-capita income level (virtual variable, 1 refers to a poor family), whether the mother is at home (virtual variable), whether it is currently an only child and whether there is running water and toilet in the home. $X_{c}$ indicates the impact of the community environment mainly the infrastructure of the community, which is mainly reflected in the urban-rural differences (virtual variables).

\section{Data source and description}

The data used in the study are from the Institute of Nutrition and Food Hygiene of the Chinese Academy of Preventive Medicine and the Family Nutrition and Health Survey Database (CHNS) conducted by the University of North Carolina in nine provinces and autonomous regions of China. The database includes the survey data of health and nutrition status of residents in nine provinces of China for the past seven years, with surveying annually about 4,000 households and involving more than 13,000 family members. This study mainly uses the 2016 children's nutritional health data in the database to make quantitative analysis, combined with children's household survey data and parental situation.

\footnotetext{
* Corresponding author: Liyi@hus.edu.cn
} 


\subsection{Children's Family Situation Description}

\subsubsection{Family Structure}

Number of children in the family: 1195 households have only 1 child, 310 households have 2 children, 34 households have 9 children, 8 families have 4 children, and 1 family has 5 children. Among them, compared with rural areas, the number of children in urban areas is relatively small, and the proportion of families with only one child is relatively large.

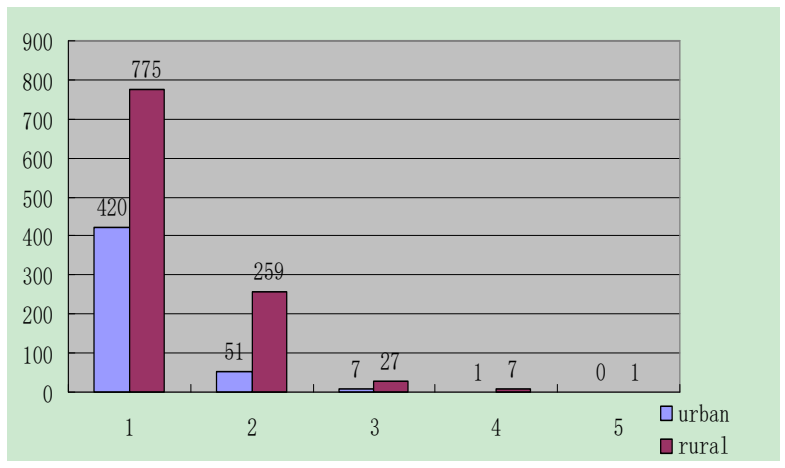

Fig.1. Differences in the size of children in urban and rural households

\subsubsection{Family Income}

The situation of household income: Although the average per-capita net income of urban and rural children's families reached 64,511.951 yuan and 5,609.769 yuan respectively. But according to the per-capita income of 958 yuan in 2016 as the poverty line, with the consideration of family size, there is still a $16 \%$ incidence of poverty and a poverty gap of $7.9 \%$.

Table 1. Differences in household income between urban and

\begin{tabular}{|l|l|l|l|l|l|}
\hline & $\begin{array}{l}\text { Sample } \\
\text { size }\end{array}$ & Mean & $\begin{array}{l}\text { standard } \\
\text { deviation }\end{array}$ & minimum & maximum \\
\hline city & 504 & 6451.951 & 7166.047 & -688.788 & 85873.33 \\
& & & & & \\
\hline Rural & 1301 & 4227.48 & 5609.769 & -612.667 & 124570.8 \\
& & & & & \\
\hline
\end{tabular}

Table 2. Description of poverty in urban and rural children

\begin{tabular}{|l|l|l|l|l|l|}
\hline indicators & P0 & P1 & P2 & SEN & SST \\
\hline $\begin{array}{l}\text { General } \\
\text { numerical }\end{array}$ & 0.16 & 0.079 & 0.059 & 11.072 & 0.111 \\
\hline $\begin{array}{l}\text { City } \\
\text { numerical }\end{array}$ & 0.116 & 0.078 & 0.064 & 9.789 & 0.013 \\
\hline
\end{tabular}

\begin{tabular}{|l|l|l|l|l|l|}
\hline $\begin{array}{l}\text { Rural } \\
\text { numerical }\end{array}$ & 0.176 & 0.079 & 0.057 & 11.324 & 0.098 \\
& & & & & \\
& & & & & \\
\hline
\end{tabular}

\subsubsection{Family Environment}

There is a low popularity of flush toilets, with only 655 households having flush toilets, and only 388 households having no running water. In addition, most families have their own housing, and only 60 families live in rented houses. From the comparison of urban and rural areas, urban households have better sanitation status and a higher proportion of flush toilets and running water.

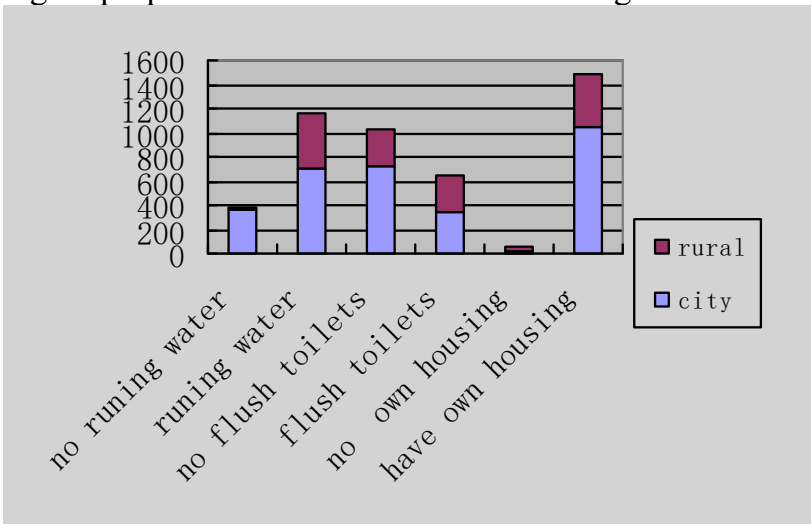

Fig.2. Compare the family environment of children in urban and rural areas

\subsection{Children's health level}

\subsubsection{Height for Age Grade for children aged 0-5}

Height and age indicators for children aged 0-5 are also recommended by the World Health Organization in 2006. The calculation formula for $z$-score is as follows: $\mathrm{Z}$-score $=$ (child height - average height of children of this age) / average height of children of this age. The probability density distribution of z-score is close to the normal distribution. The average $z$-score of urban children is 0.0767919 , and that of rural children is -0.02266 . The overall mean is very close to 0 . This shows that the average height of urban children is higher than that of rural children. The difference in height between rural children is large, and the absolute values of the highest and lowest values are higher than those of urban children.

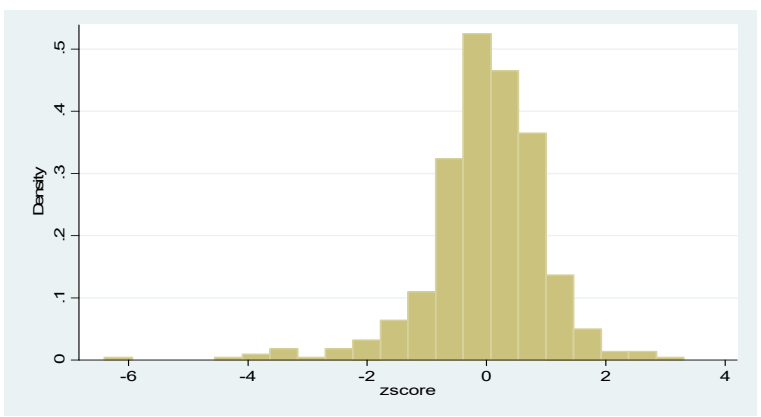

Fig. 3. The distribution of height and age scores of children aged 0-5 in the sample 


\subsubsection{Malnutrition of children aged 0-5}

Since malnutrition is defined when the z-score value is less than -2 , by calculating the $z$-score value, it can be concluded that only 16 children aged $0-5$ in the sample area have suffered malnutrition, of which 10 are from rural areas, 6 from urban areas, the average incidence of malnutrition is $2.3 \%$ and $4.4 \%$, indicating that the overall development of children in China is good.

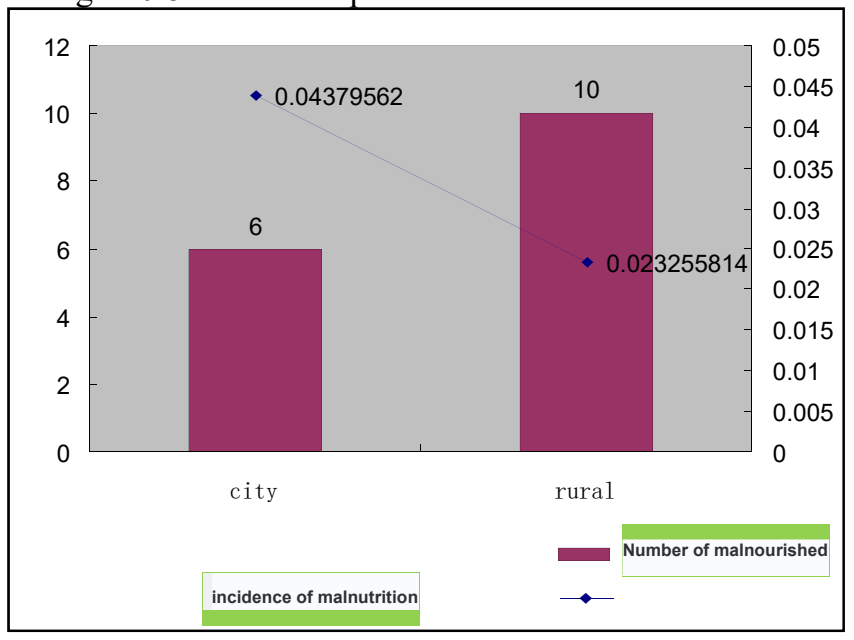

Fig. 4.Child malnutrition

\subsubsection{Body mass index for children aged 6-18}

Body mass index reflects the relationship between body weight and height. The formula is body mass index = weight $(\mathrm{kg}) /$ height2 $(\mathrm{m})$. This indicator is used to measure the nutrition and health status of school-age children because it reflects the children's body shape to a certain extent and the improvement of body mass index can be regarded as the basic basis for the improvement of children's health.

The average body mass index of children aged 6-18 in China is 19.44. Specifically, the urban-rural differences in the body mass index of children in different provinces are not obvious. Only the children from rural areas in Guangxi have significantly higher body mass index than those from other regions, which may be the result of abnormal values or special circumstances. However, in general, the indicator has little difference between urban and rural areas, and regional differences are not particularly significant.

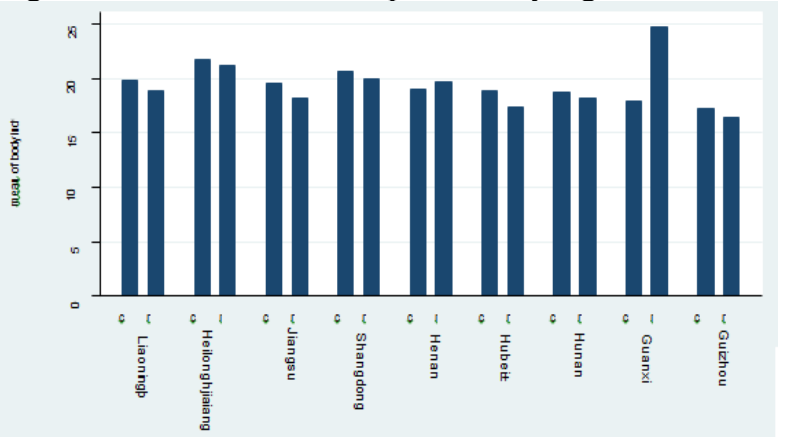

Fig. 5. Differences in body mass index of children aged 6 to 18 in different provinces

\subsubsection{Children's medical insurance}

As a social security, medical insurance can reduce the burden on families when the disease occurs. If children have medical insurance, it probably means reducing the cost of treatment for children and promoting timely treatment. As far as the sample is concerned, only $38.02 \%$ of the children have medical insurance, of which $73.3 \%$ of the children in rural areas do not have medical insurance, and $57.60 \%$ of urban children do not have medical insurance.

Medical insurance is closely related to the financial situation and policy formulation of local governments, so it is necessary to distinguish the situation of each province when inspecting the distribution of medical insurance. In terms of the coverage of medical insurance, the coverage of child medical insurance in Guizhou Province is the highest, and the lowest in Hunan Province. At the same time, the urban-rural differences in medical insurance are not the same. The coverage of children's medical insurance in Henan and Guizhou provinces is lower than that in rural areas. The coverage of urban and rural children's medical insurance in Hubei and Hunan provinces is the same. The coverage of urban children's medical insurance in other areas is much higher than that in rural areas. Heilongjiang Province has the biggest gap with about $95 \%$ of children in urban areas having medical insurance, while only $41 \%$ of rural children have medical insurance.

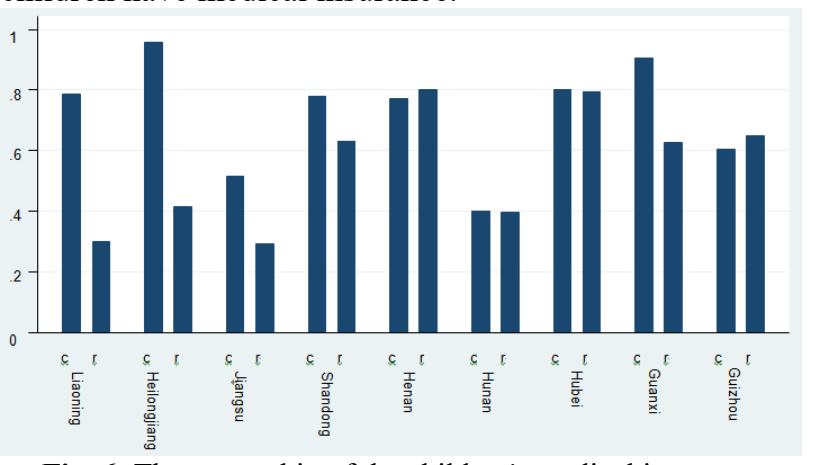

Fig. 6. The ownership of the children's medical insurance

\section{Pirical analysis and conclusion}

Table 1 shows the regression results of the quantitative model of nutrition and health of children in China. Mo 
affects the child's nutritional dell is to regress by taking whether age, gender, whether it is left-behind children, whether the family is poor, whether the family has tap water, whether there is a flush toilet, whether it is an only child, whether it comes from rural areas as an independent variable. Model 2 further transforms this variable of whether it is from poor households into the household income and is divided into four groups: low-income group, middle-income group, middle-income group and high-income group, and then the regression is taken with additional independent variables of whether the child has medical insurance and whether to participate in health care services. Since Model 1 and Model 2 do not explain the dependent variables much, the provincial dummy variables are added to Model 3 for regression. The analysis of the regression results is as follows:

Firstly, the overall R2 of the the three regression models after adjustment is not high, indicating that the explanatory power of the model is not very high, but the $\mathrm{F}$ test shows that the overall regression results of the model are significant. Secondly, gender has a significant impact on age-specific height. The Height for Age Grade of boys is generally better than that of girls. It is also found that the average height of girls is significantly lower than that of boys. Thirdly, whether it is a left-behind child, and whether it is an only child and family income all have a significant impact on children's health. However, there are multiple correlations between parents' absences, family income and child care, which may lead to inaccuracies in the regression results. And having medical insurance can make children's diseases get timely treatment and promote their health. By dividing the household per-capita income into four groups from high to low, the impact of income on children's health has become more significant. In addition, the health status of the child's family also affects the child's nutritional health, but this regression may not be accurate. For example, whether there is a flush toilet in the home may be related to whether the family lives in the rural area, and further research is needed. Finally, the nutritional health of children in different provinces is also different, which is consistent with the description and analysis. As we all know, the average height of the north is higher than that of the south. This article uses height and age as a measure of children's nutritional health, so the geographical characteristics of height also affect the research conclusions. However, after the addition of the provincial virtual variable, the regression results of the model have greatly changed. At the same time, the influences among the virtual variables in the provinces are significantly strong, which indicates that the degree of variation between the provinces is not very high, and the samples still have strong representativeness.

It is noteworthy that the implementation of the family planning policy in our country has led to a decrease in the number of children in the family, and the nutritional status of the only child is better than that of other children. In addition, the problem of left-behind children is also worthy of attention. Parents' frequent absences have a great impact on the nutritional health of children.
Table 3. Results of regression analysis of each model

\begin{tabular}{|c|c|c|c|}
\hline $\begin{array}{l}\text { Variable } \\
\text { Name }\end{array}$ & Model 1 & Model 2 & Model 3 \\
\hline F Test & $8.63^{* *}$ & $7.63^{* *}$ & $13.21^{* *}$ \\
\hline Adjustment $\mathrm{R}^{2}$ & 0.0906 & 0.0932 & 0.1029 \\
\hline Constant & $\begin{array}{r}-0.14569 \\
(0.127)\end{array}$ & $\begin{array}{c}-0.2493 \\
(0.013)^{*}\end{array}$ & $\begin{array}{r}0.165742 \\
(0.186)\end{array}$ \\
\hline $\begin{array}{l}\text { Whether from } \\
\text { uralarea }\end{array}$ & $\begin{array}{r}-0.06447 \\
(0.247) \\
\end{array}$ & $\begin{array}{r}-0.08317 \\
(0.142) \\
\end{array}$ & $\begin{array}{r}-0.06958 \\
(0.201) \\
\end{array}$ \\
\hline gender & $0.272212(0.039)$ & $\begin{array}{l}0.2749 \\
(0.027)^{* *}\end{array}$ & $\begin{array}{l}0.27762 \\
(0.036)^{* *}\end{array}$ \\
\hline Only child & $0.174897(0.02)$ & $\begin{array}{l}0.15303(0.00 \\
2)^{* * *}\end{array}$ & $\begin{array}{c}0.019648 \\
(0.031)^{* *}\end{array}$ \\
\hline age & $\begin{array}{r}-0.00283 \\
(0.567)\end{array}$ & $\begin{array}{r}-0.00437 \\
(0.382)\end{array}$ & $\begin{array}{r}-0.00598 \\
(0.226)\end{array}$ \\
\hline $\begin{array}{l}\text { Whether to } \\
\text { have drinking } \\
\text { water }\end{array}$ & $\begin{array}{c}-0.08135 \\
(0.16)\end{array}$ & $\begin{array}{c}-0.08984 \\
(0.12)\end{array}$ & $\begin{array}{r}0.058534 \\
(0.356)\end{array}$ \\
\hline $\begin{array}{l}\text { Whether to } \\
\text { have flush } \\
\text { toilet }\end{array}$ & $0.13054(0.012)$ & $\begin{array}{l}0.12949(0.01 \\
5)^{* *}\end{array}$ & $\begin{array}{c}0.067441 \\
(0.24)\end{array}$ \\
\hline $\begin{array}{l}\text { Whether } \\
\text { left-behind } \\
\text { child }\end{array}$ & $\begin{array}{l}-0.0955(0 \\
.019)^{* *}\end{array}$ & $\begin{array}{l}-0.07873(0.0 \\
39)^{* *}\end{array}$ & $\begin{array}{c}0.006311 \\
(0.018) * *\end{array}$ \\
\hline $\begin{array}{l}\text { Whether from } \\
\text { a poor family }\end{array}$ & $-0.05149(0.483)$ & & \\
\hline \multicolumn{2}{|c|}{ Family income group } & $\begin{array}{l}0.048196(0.0 \\
36)^{* *}\end{array}$ & $\begin{array}{r}0.027037 \\
(0.228)\end{array}$ \\
\hline \multicolumn{2}{|c|}{ Whether to have medical insurance } & $\begin{array}{l}0.104361(0.0 \\
32)^{* *}\end{array}$ & $\begin{array}{c}0.032385 \\
(0.5)\end{array}$ \\
\hline \multicolumn{2}{|c|}{ Whether to participate in health care } & $\begin{array}{l}-0.0539(0.60 \\
5)\end{array}$ & $\begin{array}{r}-0.09264 \\
(0.362)\end{array}$ \\
\hline \multicolumn{4}{|c|}{ Provincial dummy variable } \\
\hline \multicolumn{4}{|c|}{ Control group: Liaoning Province } \\
\hline \multicolumn{3}{|c|}{ Heilongjiang Province } & $\begin{array}{r}-0.09603 \\
(0.337)\end{array}$ \\
\hline \multicolumn{3}{|c|}{ Jiangsu Province } & $\begin{array}{r}0.012047 \\
(0.898) \\
\end{array}$ \\
\hline \multicolumn{3}{|c|}{ Shandong Province } & $\begin{array}{l}-0.10706 \\
(0.323)\end{array}$ \\
\hline \multicolumn{3}{|l|}{ Henan Province } & $\begin{array}{l}-0.34827(0.0 \\
02)^{* *}\end{array}$ \\
\hline \multicolumn{3}{|l|}{ Hubei Province } & $\begin{array}{l}-0.39941(0.0 \\
00)^{* *}\end{array}$ \\
\hline \multicolumn{3}{|c|}{ Hunan Province } & $\begin{array}{l}-0.39726 \\
(0.000)^{* * *}\end{array}$ \\
\hline \multicolumn{3}{|c|}{ Guangxi Province } & $\begin{array}{l}-0.4939 \\
(0.000)^{* *}\end{array}$ \\
\hline \multicolumn{3}{|c|}{ Guizhou Province } & $\begin{array}{l}-0.78966 \\
(0.000)^{* * *}\end{array}$ \\
\hline
\end{tabular}

\section{References:}

1. De Onis,M;Fongillo,E. and M. Blossener. Is Malnutrition Declining? An Analysis of Changes in Level of Malnutrition Since 1980. Bulletin of the World Health Organization,2000(78)

2. Mushkin.S.J. "Health as an investment" Journal of Political Economy, 1962

3. Chen Zaiyu, Analysis of nutrition and status of left-behind children in rural areas in China. China Population Science, 2009 (5)

4. Song Yuepin, Rural Children's Health in China: Analysis of Affecting Factors from Family and Community. China Rural Economy, 2007(10) 